\title{
FACTORS AND THEIR INFLUENCE IN DEVELOPING FOOD COOPERATIVES
}

\author{
Anna Florek-Paszkowska ${ }^{1}$, Androniki Kavoura ${ }^{2}$ \\ ${ }^{1}$ Jagiellonian University (Poland), greda.anna@gmail.com, anna.florek-paszkowska@uj.edu.pl \\ ${ }^{2}$ Technological Educational Institute of Athens (Greece), nkavoura@teiath.gr
}

\begin{abstract}
Consumption saving practices are the community response in cities to the crisis that hit Europe and has caused the reactivation and creation a new form of food cooperatives. Consumer cooperative movement has a long tradition in Poland dating back to 1816. The first consumer cooperative, "Mercury", was founded in 1869 in Warsaw, while the first food cooperative associations were established in the 1906. Political events in our country after 1945 caused the interruption of the cooperative tradition. The current model of food cooperatives, as informal initiatives is a completely new phenomenon in Poland. Such a society for the first time was established at the beginning of 2010. It was the Warsaw Food Cooperative. Currently, in Poland there are about thirty informal food cooperatives. Worldwide, cooperatives have more than 1 billion members. Agricultural and food cooperatives represent a significant portion of the global cooperative sector in developed and developing countries. The paper presents the application of the Analytic Network Process (ANP) in prioritization of crucial factors that affect stakeholders involved in food cooperative development. The research was made based on questionnaires with experts (members and owners) of „,consumption oriented“ food cooperatives in the Lesser Poland Voivodeship.
\end{abstract}

Keywords: food cooperatives, food co-op, social activities, Analytic Network Process, ANP

\section{Introduction}

In Poland, the tradition of functioning the cooperative movement dates back to 1816. It slowly disappeared in the Polish People's Republic, because it was subjected to the processes of nationalization, centralization, bureaucracy and forced the monopolization of certain areas of economic life. At that time the cooperative was a tool of the state-party power [Brzozowska J., 2007, p. 33], which led to the disappearance of the original idea of the cooperative movement and the emergence of a caricature of its image. After many years of the negative image of cooperatives in the eyes of Poles, currently cooperatives' image is undergoing gradual transformation and reactivation, and is beginning to take on a new dimension. Since 2010 we can observe a "come back" of a new type of cooperative and characteristic "sprouting" of civil society [Bilewicz A., Potkanska D., 2013, p. 25] that is guided by the idea of cooperative of the nineteenth century. We are talking about the phenomenon of the "new cooperativism" [Vieta M., 2010, p. 2].

Cooperatives are informal and non-profit organizations. The number of food co-operatives in Poland amounts to approximately $30^{1}$. Food cooperatives in Poland can be divided into: "activist" and "oriented on consumption". In the latter type of cooperatives, members' activity is mostly virtual, and membership consists of signing up to a group on the social network and picking up their products in an appointed place.

Their formation results from several factors, including: increasing awareness of healthy nourishment principles among people. This is especially true among those who have children, or suffer from food allergies - they avoid purchasing mass-produced, low-quality food with a lot of chemical additives.

${ }^{1}$ https://kolektywnie.wordpress.com/ 
Food price is one of the most important factors for the consumer. Based on this, doing shopping in food cooperatives is a good choice, because: (1) it allows you to make purchases of local, seasonal foods without intermediaries (straight from a local producer / farmer) at a lower cost; (2) it supports local agriculture and entrepreneurship, and thus it leads to regional development; (3) it leads to supportive cooperation and integration of the local community; (4) it protects the natural environment by reducing the so-called foodmiles, due to the local purchases; (4) it promotes and develops the cooperative idea.

In Brazil, 37 percent of agricultural GDP is produced through cooperatives; in Egypt, 4 million farmers earn their income through cooperative membership; in Ethiopia the equivalent figure is 900000 ; and in India, 16.5 million litres of milk are collected every day from 12 million farmers in dairy cooperatives. In Europe, agricultural cooperatives have an overall market share of about 60 percent of the processing and marketing of agricultural commodities and about 50 percent of the supply of inputs ${ }^{2}$.

Consumption saving practices are the community response taken in cities to the crisis that was hit Europe in economic and social terms. Other forms of social activity are e.g.: clothes exchange fairs, car sharing. Rachel Botsman and Roo Rogers (2010) noted that the community saving practices also create new forms of participation in economic and social life, which can permanently affect changes in the way of life in cities.

\section{Data/Model Analysis}

This study presents an application one of the most advanced and popular decision making techniques Analytic Network Process (ANP) [Florek-Paszkowska A., Cymanow P., Cymanow-Sosin K., 2014] to answer the question: "which factors and how strongly influence the stakeholders involved in food cooperatives?". We have grouped factors into clusters of: social, marketing, economic, ecological, technological, production, communication, educational and legal factors. The ANP network model includes 44 elements, which present inner- and outer dependence between the groups. The researches used the questionnaires with experts (members and owners) of "consumption oriented" food cooperatives in Lesser Poland Voivodeship. There weights were calculated based on pairwise comparisons of connected and influenced elements using Saaty's fundamental scale.

Because of the pages limitation of this paper, the ANP model and results, will be given in the full paper.

\section{Conclusions}

To sum up, technological development, demographic changes, the growing power of social media and social initiatives e.g. open food cooperatives will create new opportunities in the next few years, so that everyone will be able to choose if they want to live in a more conscious way. In order to survive, developed and attract new members - the sine qua non for food cooperatives is to follow the changing trends and consumer expectations, especially concerning forms of communication or card payments (one of the co-operative principles is cash payment), or generally speaking - adaptation of the old cooperative principles to the new realities of the digital age.

\section{References}

Bilewicz A., Potkanska D. 2013. „How civil society sprouts". Third Sector. PRISM . 31 (3): 25-44 (in Polish).

Botsman, R., Rogers, R., 2010, What's mine is yours: The rise of collaborative consumption (Harper Business, New York).

Brzozowska J. 2007. "Cooperative as a subject of social economy." Social Economy 1 (1): 33-41. Cracow. Cracow University of Economics. Public School of Administration (in Polish).

Florek-Paszkowska, A., Cymanow, P., Cymanow-Sosin, K., 2014, Multi-criteria assessment of risk in the management of a food industry enterprise with the application of the Analytic Network Process. International Journal of Advanced Technology in Engineering and Science. 2(12), 207-214.

\footnotetext{
${ }^{2}$ http://www.fao.org/partnerships/cooperatives/en [27.09.2015].
} 
http://www.fao.org/partnerships/cooperatives/en [27.09.2015].

https://kolektywnie.wordpress.com/

Vieta Marcelo (Ed.). 2010. "The New Cooperativism". Affinities: A Journal of Radical Theory, Culture, and Action. Vol. 4, 1: 1-11. 